Article

\title{
The Prediction Methods for Potential Suspended Solids Clogging Types during Managed Aquifer Recharge
}

\author{
Xinqiang Du, Yunqing Fang, Zijia Wang *, Jiawei Hou and Xueyan Ye \\ Key Laboratory of Groundwater Resources and Environment, Ministry of Education, Jilin University, \\ Changchun 130021, China; E-Mails: duxq77@163.com (X.D.); fangyunqing100@126.com (Y.F.); \\ houjw1990@163.com (J.H.); yexy@jlu.edu.cn (X.Y.) \\ * Author to whom correspondence should be addressed; E-Mail: wangzj821@163.com; \\ Tel.: +86-431-8850-2850; Fax: +86-431-8850-2850.
}

Received: 17 February 2014; in revised form: 24 March 2014 / Accepted: 11 April 2014 / Published: 22 April 2014

Abstract: The implementation and development of managed aquifer recharge (MAR) have been limited by the clogging attributed to physical, chemical, and biological reactions. In application field of MAR, physical clogging is usually the dominant type. Although numerous studies on the physical clogging mechanism during MAR are available, studies on the more detailed suspended clogging types and its prediction methods still remain few. In this study, a series of column experiments were inducted to show the process of suspended solids clogging process. The suspended solids clogging was divided into three types of surface clogging, inner clogging and mixed clogging based on the different clogging characteristics. Surface clogging indicates that the suspended solids are intercepted by the medium surface when suspended solids grain diameter is larger than pore diameter of infiltration medium. Inner clogging indicates that the suspended solids particles could transport through the infiltration medium. Mixed clogging refers to the comprehensive performance of surface clogging and inner clogging. Each suspended solids clogging type has the different clogging position, different changing laws of hydraulic conductivity and different deposition profile of suspended solids. Based on the experiment data, the ratio of effective medium pore diameter $\left(D_{p}\right)$ and median grain size of suspended solids $\left(\mathrm{d}_{50}\right)$ was proposed as the judgment index for suspended solids clogging types. Surface clogging occurred while $\mathrm{D}_{\mathrm{p}} / \mathrm{d}_{50}$ was less than 5.5 , inner clogging occurred while $\mathrm{D}_{\mathrm{p}} / \mathrm{d}_{50}$ was greater than 180 , and mixed clogging occurred while $\mathrm{D}_{\mathrm{p}} / \mathrm{d}_{50}$ was between 5.5 and 180. In order to improve the judgment accuracy and applicability, Bayesian method, which considered more ratios of medium pore diameter $\left(D_{p}\right)$ and different level of grain diameter of 
suspended solids $\left(\mathrm{d}_{\mathrm{i}}\right)$, were developed to predict the potential suspended solids types.

Keywords: managed aquifer recharge; suspended solids; physical clogging

\section{Introduction}

With the background of global water scarcity, actively promoting water reuse and excess water storage technology helps solve the problem of groundwater and surface water shortage attributed to uncertain climatic factors. Managed aquifer recharge (MAR) is one of the most effective methods to augment the groundwater resources [1-3]. It may form part of conjunctive use schemes, or be applied to increase water availability and improve water quality.

Conventional recharge water resources including native groundwater, potable water and surface water were primarily used in MAR. In recent years, with the growing interest in non-conventional resources, quality and health issues have been raised [4]. Improvements to water quality via MAR have been demonstrated to reduce organic matter [5,6], trace organic compounds [7], nitrogen [8]. Bacteria and virus transport during MAR is another one major concern with using recycled water [9-11]. The water quality change and its related health risks still are the main topics for MAR researches.

Clogging issue has been another main limited factor for the implementation of MAR around the world. According to the investigation on 207 groundwater recharge systems in Maryland, USA, the rate of loss function system attributed to clogging increased to 50\% in 1990 from $33 \%$ in 1986 [12]. Clogging is generally caused by inter-dependent mechanisms that are often hard to distinguish [13-15]. The classification of clogging into physical, chemical and biological processes is quite standard [16]. The role of suspended particles in clogging was recognized early and was often evidenced as the main clogging mode during MAR process [17-19]. It has been observed to depend on the total mass of suspended solids and particle size distribution of the porous media with reduction in basin recharge rates well described by an exponential decay function [20]. The main source of suspended solids mainly comes from recharge water and may also generates from aquifer matrix because of hydrodynamic and hydrochemical function [21,22]. The mechanisms of suspended solids clogging including filtration and deposition function. Modified fouling index (MFI) was mainly used to assess clogging potential of artificial recharge well [23]. Turbidity and concentration of suspended solids of recharge water are the main two common water quality indexes to assess potential of clogging [24,25]. But the judgment criterion for suspended solids clogging is still not uniform. Siriwardene NR et al. (2007) showed that physical clogging was mainly caused by the migration of sediment particles that are less than $6 \mu \mathrm{m}$ in diameter [26]. Okubo and Matsumoto (1983) showed that physical clogging problems would not occur if the suspended solids (SS) level of recharge water utilized for ASR is $<2 \mathrm{mg} / \mathrm{L}$ [27]. However, Pavelic et al. (1998) showed that physical clogging problems did not exhibited at a stormwater MAR site in South Australia even when SS $>25 \mathrm{mg} / \mathrm{L}$ [22]. The recommend limitation of TSS $<100 \mathrm{mg} / \mathrm{L}$ was proposed by Winter (2013) [28]. These experiments were conducted to study the MAR clogging problem from the perspective of the nature of suspended solids and do not comprehensively consider the properties of porous media. Thus, the proposed criteria are mostly applicable at limited field conditions. This article was tried to give a more detailed classification for 
suspended solids clogging and propose prediction methods to predict the potential clogging types. This would be helpful to prevent and control suspended solids clogging during MAR design and operation.

\section{Materials and Methods}

\subsection{Lab-Based Approach}

A MAR laboratory experimental system included four parts: water supply tank with circulation function (includes a submersible pump with a maximum pump head of $5 \mathrm{~m}$ and maximum output $5500 \mathrm{~L} / \mathrm{h}$ ), upper and lower constant-head controller for water supply and drainage (adjustable range is 0 to $1.5 \mathrm{~m}$ ), experimental seepage column $(580 \mathrm{~mm}$ in height and with $80 \mathrm{~mm}$ inside diameter and is made of Plexiglas), and pressure observation panel. Piezometer tubes were distributed along the experimental column (Figure 1).

Figure 1. Schematic diagram of aquifer recharge managed simulated system.

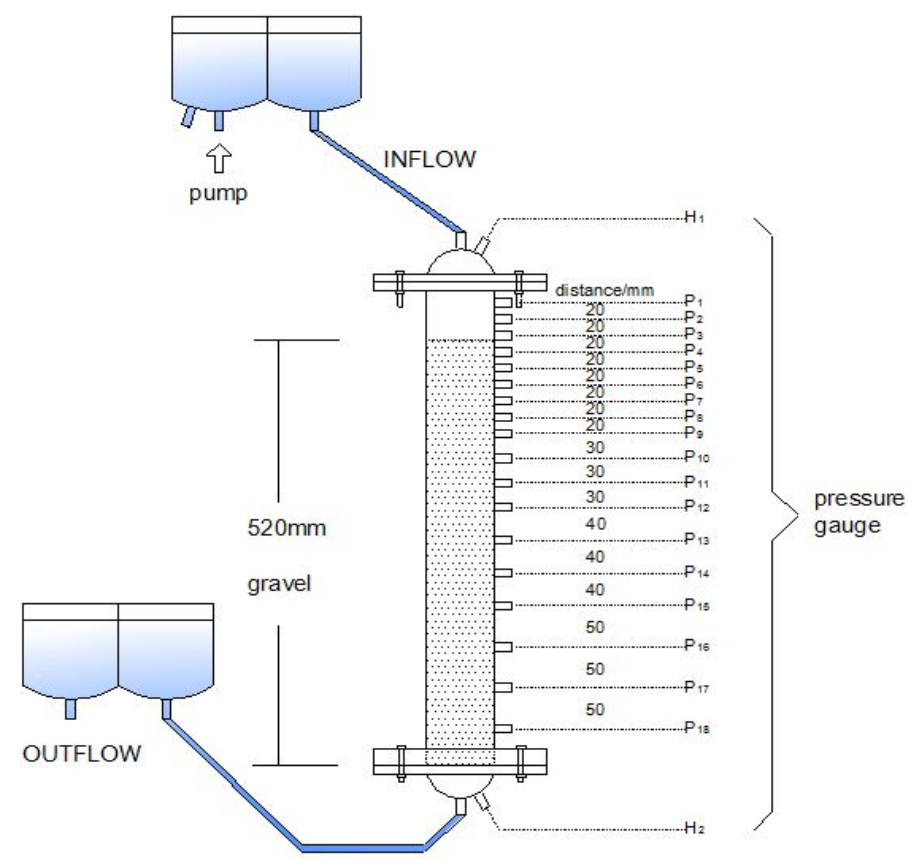

Highly purified Quartz sand and river sand (predominant mineral composition was quartz, with a small amount of feldspar) were adopted as the infiltration medium. The columns were packed with quartz sand in increments of $1 \mathrm{~cm}$ according to its natural density of $1.6 \mathrm{~g} / \mathrm{cm}^{3}$.

The suspended solids were collected from lowlands of a field site after a storm event. The particle diameter distribution was measured by TCZ-4 particle analyzer and showed in Figure 2. The coarse particles of diameter greater than $0.1 \mathrm{~mm}$ were removed because this part is easily to removal by pretreatment. All the selected suspended solids samples were mixed together. X-ray diffraction (XRD) pattern showed that dominant mineral composition is quartz, Alkali feldspar and Plagioclase (Table 1).

The ultra-purified water was produced by machine of ELGA Option R7 and the main characteristics are as follow: TSS $=0 \mathrm{mg} / \mathrm{L}$, TDS $=0 \mathrm{mg} / \mathrm{L}$ to $2 \mathrm{mg} / \mathrm{L}$. The recharge water adopted in these lab experiments was mixed sieved suspended solids and ultra-purified water with total suspended solids (TSS) equals to $1000 \mathrm{mg} / \mathrm{L}$ and total dissolved solids (TDS) equals to $4 \mathrm{mg} / \mathrm{L}$ to $6 \mathrm{mg} / \mathrm{L}$. 
Table 1. Mineralogy of suspended solids.

\begin{tabular}{cccccccccc}
\hline Sample No. & SS1 & SS2 & SS3 & SS4 & SS5 & SS6 & SS7 & SS8 & SS9 \\
\hline Quartz & 37 & 42 & 46 & 47 & 38 & 43 & 56 & 47 & 49 \\
Alkali feldspar & 11 & 16 & 17 & 22 & 11 & 14 & 10 & 14 & 15 \\
Plagioclase & 20 & 23 & 21 & 22 & 18 & 30 & 21 & 22 & 21 \\
Calcite & 8 & 3 & 4 & 4 & 4 & 2 & 4 & 8 & 6 \\
Illite-smectite mixed-layer & 6 & 2 & 2 & 0 & 4 & 3 & 3 & 4 & 0 \\
Illite & 12 & 8 & 6 & 0 & 15 & 5 & 2 & 0 & 6 \\
Kaolinite & 5 & 5 & 3 & 4 & 9 & 3 & 4 & 4 & 3 \\
Amphibole & 1 & 1 & 1 & 1 & 1 & 0 & 0 & 1 & 0 \\
\hline
\end{tabular}

Figure 2. Particle diameter distribution of suspended solids.

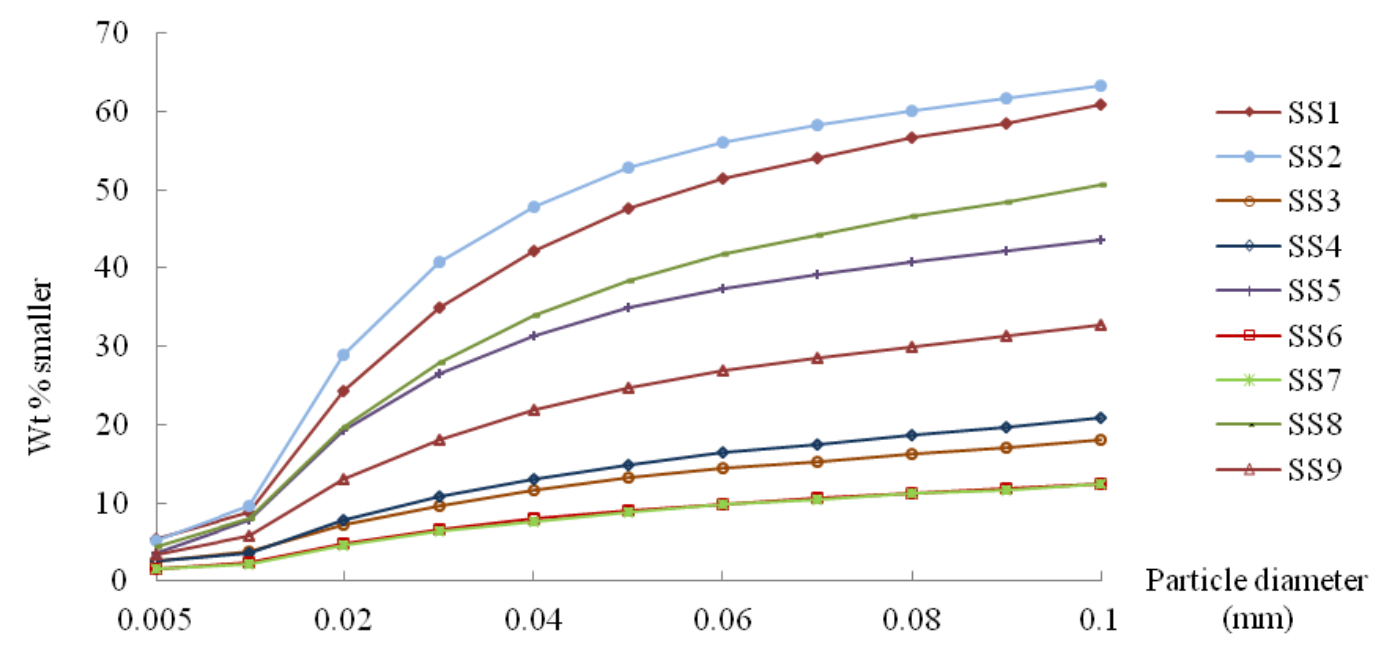

The recharge water was feed up from a water tank to the upper constant head controller, flow throughout the column and then discharge via the lower constant head controller. The columns were initially flushed for $4 \mathrm{~h}$ with purified water before the experiments to clear any potential pollutants in the infiltration sand. During the operation period, a submersible pump was placed at the bottom of water tank and was used to continuously feed water into the upper constant-head water level controller; the water infiltrated through the columns at a hydraulic gradient of 1 . Surplus water overflowed from the upper level controller and was recycled into the water tank.

The flow rate and hydraulic head along the infiltration path were observed every $2 \mathrm{~h}$ or $4 \mathrm{~h}$ manually. TDS was measured using a Multi-parameter Water Quality Portable Meter every $2 \mathrm{~h}$. TSS of inflow and outflow was measured using a PARTECH 740 monitor every $2 \mathrm{~h}$. The time-varying hydraulic conductivity at different positions of the sand columns was calculated based on Darcy's law (Equation (1)):

$$
K=\frac{Q l}{\pi r^{2} \Delta h}
$$

where $Q\left(\mathrm{~m}^{3} / \mathrm{d}\right)$ is the flow rate; $l(\mathrm{~m})$ is the distance between any two piezometric tubes along the column; $\Delta h(\mathrm{~m})$ is the hydraulic head difference at a distance of $l$; and $r(\mathrm{~m})$ is the inner diameter of the column. The clogging degree at different position can be expressed by the ratio of hydraulic 
conductivity $(K)$ and its initial hydraulic conductivity $\left(\mathrm{K}_{0}\right)$. If the value of $K / \mathrm{K}_{0}$ is less than 1 , that means clogging has happened at the specific time and specific position.

At the end of experiment, the sand in column was excavated one centimeter at a time. The suspended solids were separated from each sand sample through the procedures of wash, separation, drying and weight.

Seventeen experiments (Table 2) were conducted to simulate the suspended solids clogging process. Coarse sand (I) (sieve number 10 to 20), coarse sand (II) (sieve number 20 to 40), medium sand (sieve number 40 to 70 ), fine sand (sieve number 70 to 150), and mixed sand (sieve number 20 to 150 with equal amounts of fine sand, medium sand, and coarse sand (II)) were adopted as the infiltration medium. The grain diameters of suspended solids in recharged water were $0.075 \mathrm{~mm}$ to $0.05 \mathrm{~mm}, 0.05 \mathrm{~mm}$ to $0.0385 \mathrm{~mm}$, less than $0.0385 \mathrm{~mm}$, and less than $0.013 \mathrm{~mm}$.

Table 2. Ratios of infiltration medium effective pore diameter $\left(D_{p}\right)$ and levels of suspended solids grain diameter $\left(\mathrm{d}_{\mathrm{i}}\right)$.

\begin{tabular}{|c|c|c|c|c|c|c|c|c|c|c|c|}
\hline $\begin{array}{c}\text { Experiment } \\
\text { No. }\end{array}$ & $\begin{array}{c}\text { Medium and } D_{p} \\
(\mathrm{~mm})\end{array}$ & $d_{i}(\mathbf{m m})$ & $\mathbf{D}_{\mathrm{p}} / \mathbf{d}_{10}$ & $\mathbf{D}_{\mathrm{p}} / \mathbf{d}_{\mathbf{2 0}}$ & $\mathbf{D}_{\mathrm{p}} / \mathbf{d}_{30}$ & $\mathbf{D}_{\mathrm{p}} / \mathbf{d}_{40}$ & $\mathbf{D}_{\mathrm{p}} / \mathbf{d}_{50}$ & $\mathbf{D}_{\mathrm{p}} / \mathbf{d}_{60}$ & $\mathbf{D}_{\mathrm{p}} / \mathbf{d}_{70}$ & $\mathbf{D}_{\mathrm{p}} / \mathbf{d}_{\mathbf{8 0}}$ & $\mathbf{D}_{\mathrm{p}} / \mathbf{d}_{90}$ \\
\hline E2 & $\begin{array}{c}\text { Coarse sand (I), } \\
0.453\end{array}$ & $<0.013$ & 453.0 & 348.5 & 266.5 & 215.7 & 181.2 & 151.0 & 129.5 & 105.4 & 80.89 \\
\hline E4 & & $0.075-0.05$ & 2.08 & 2.00 & 1.93 & 1.86 & 1.77 & 1.71 & 1.64 & 1.59 & 1.52 \\
\hline E5 & Coarse sand (II), & $0.05-0.0385$ & 2.77 & 2.70 & 2.63 & 2.57 & 2.51 & 2.45 & 2.35 & 2.30 & 2.25 \\
\hline E6 & 0.108 & $<0.0385$ & 13.50 & 12.00 & 10.80 & 9.82 & 8.31 & 7.20 & 6.35 & 5.40 & 4.15 \\
\hline E7 & & $<0.013$ & 108.0 & 83.08 & 63.53 & 51.43 & 43.20 & 36.00 & 30.86 & 25.12 & 19.29 \\
\hline E9 & & $0.075-0.05$ & 1.27 & 1.22 & 1.18 & 1.14 & 1.08 & 1.05 & 1.00 & 0.97 & 0.93 \\
\hline E10 & Medium sand, & $0.05-0.0385$ & 1.69 & 1.65 & 1.61 & 1.57 & 1.53 & 1.50 & 1.43 & 1.40 & 1.38 \\
\hline E11 & 0.066 & $<0.0385$ & 8.25 & 7.33 & 6.60 & 6.00 & 5.08 & 4.40 & 3.88 & 3.30 & 2.54 \\
\hline E12 & & $<0.013$ & 66.00 & 50.77 & 38.82 & 31.43 & 26.40 & 22.00 & 18.86 & 15.35 & 11.79 \\
\hline E14 & & $0.075-0.05$ & 0.88 & 0.85 & 0.82 & 0.79 & 0.75 & 0.73 & 0.70 & 0.68 & 0.65 \\
\hline E15 & Fine sand, & $0.05-0.0385$ & 1.18 & 1.15 & 1.12 & 1.10 & 1.07 & 1.05 & 1.00 & 0.98 & 0.96 \\
\hline E16 & 0.046 & $<0.0385$ & 5.75 & 5.11 & 4.60 & 4.18 & 3.54 & 3.07 & 2.71 & 2.30 & 1.77 \\
\hline E17 & & $<0.013$ & 46.00 & 35.38 & 27.06 & 21.90 & 18.40 & 15.33 & 13.14 & 10.70 & 8.21 \\
\hline E19 & & $0.075-0.05$ & 1.50 & 1.44 & 1.39 & 1.34 & 1.28 & 1.24 & 1.18 & 1.15 & 1.10 \\
\hline E20 & Mixed sand (I), & $0.05-0.0385$ & 2.00 & 1.95 & 1.90 & 1.86 & 1.81 & 1.77 & 1.70 & 1.66 & 1.63 \\
\hline E21 & 0.078 & $<0.0385$ & 9.75 & 8.67 & 7.80 & 7.09 & 6.00 & 5.20 & 4.59 & 3.90 & 3.00 \\
\hline E22 & & $<0.013$ & 78.00 & 60.00 & 45.88 & 37.14 & 31.20 & 26.00 & 22.29 & 18.14 & 13.93 \\
\hline
\end{tabular}

Note: * Experiments of E1, E3, E8, E13 and E19 are the background references which recharge water is only ultra-purified water.

\subsection{Prediction Methods of Suspended Solids Clogging Types}

Suspended solids clogging types would be vary depending on the magnitude relation between infiltration medium pore diameter and suspended solids grain diameter. For the quantitative representation of the relationship among medium pore, suspended solids, and clogging type, the calculation for the conversion of effective grain diameter to the effective pore diameter is realized using the effective pore diameter formula (Equations (2) and (3)) proposed by Glover and Walker (2009) [29]: 


$$
D_{e f f}=2 \theta r_{e f f}=\theta D_{p}
$$

where,

$$
\theta=\sqrt{\frac{a m^{2}}{8 n^{2 m}}}
$$

where $D_{\text {eff }}(\mathrm{mm})$ is the effective grain diameter; $\theta$ (dimensionless) is the theta transform; $r_{\text {eff }}(\mathrm{mm})$ is the effective pore radius; $D_{p}(\mathrm{~mm})$ is the effective pore diameter; $a$ is a parameter thought to be equal to $8 / 3$ for three-dimensional samples composed of quasi-spherical grains; $m$ (dimensionless) is the cementation exponent; and $n$ (dimensionless) is the porosity. In this study, the prediction analysis of the suspended solids clogging type can be achieved using two methods: the ratio of infiltration medium pore diameter and suspended solids grain diameter and the Bayesian method [30] based on multi ratios of infiltration medium pore diameter and suspended solids grain diameter.

\subsubsection{Ratio of Pore Diameter $\left(D_{p}\right)$ and Grain Diameter $(d)$}

Using the ratio of infiltration medium pore diameter and a suitable suspended solids grain diameter as indicator and according to the classification results of the experimental samples, the critical value of discriminant index was determined to differentiate various types of suspended solids physical clogging.

\subsubsection{Bayesian Discrimination Method}

$\mathrm{G} 1, \mathrm{G} 2, \ldots \mathrm{Gg}$ are $\mathrm{g}$ p-dimensional normal population, and each population has equal covariance matrix. After the calculation, the Bayesian discriminant functions for multiple populations (Equation (4)) could be obtained:

$$
W_{i}(x)=\mu_{i}^{\prime} \sum^{-1} x-\frac{1}{2} \mu_{i}^{\prime} \sum^{-1} \mu_{i}+\ln q_{i} ; q_{i}=\frac{n_{i}}{n}, \quad n=\sum_{i=1}^{k} n_{i}
$$

where $q_{i}$ is prior probability of each population; and $n_{i}$ is the number contained in $i$ th population $G_{i}$.

In practical application, if $\mu_{i}$ and $\Sigma_{\mathrm{i}}$ are unknown, training samples could be used for estimation, that is, the sample average $\bar{x}^{(t)}$ and sample dispersion matrix $\mathrm{S}_{\mathrm{t}} / \mathrm{n}$ of the training samples can be used.

$$
\begin{gathered}
\hat{\mu}_{k}=\frac{1}{n_{k}} \sum_{i=1}^{n_{k}} X_{i}^{(k)}=\bar{x}^{(k)} \\
\hat{\Sigma}=\frac{\left(n_{1}-1\right) S_{1}+\left(n_{2}-1\right) S_{2}+\cdots+\left(n_{g}-1\right) S_{g}}{n_{1}+n_{2}+\cdots+n_{g}-g} \\
S_{k}=\frac{1}{n_{k}} \sum_{i=1}^{n_{k}}\left(x_{i}^{k}-\bar{x}^{(k)}\right)\left(x_{i}^{k}-\bar{x}^{(k)}\right)^{\prime}
\end{gathered}
$$

where $x_{i}^{k}$ is the $i$ th sample in the $k$ th population; $k=1,2, \ldots, \mathrm{g} ; \hat{\mu}_{k}$ is the estimate of the $k$ th population average $\mu_{k} ; \hat{\Sigma}$ is the estimate of the population covariance matrix $\Sigma$; and $S_{k}$ is the intragroup covariance matrix of number $k$ population.

If the misclassification loss is $\mathrm{c}(j \mid i)(i, j=1,2, \ldots, \mathrm{g})$, let $\mathrm{c}(i \mid i)=0$. Here, Bayesian discrimination criterion is: 


$$
\text { If } \max \left\{W_{k}(x)\right\}=W_{i}(x) x \in G_{i}
$$

The discrimination criterion could be interpreted as follows: for a given pending sample $x$, the calculated $g$ p-dimensional normal population, the maximum of which at $x W_{k}(x)$ belongs to $G_{i}$, is called the category of the pending sample.

\subsection{Case Verification}

Three experiments were conducted to simulate the suspended solids physical clogging process, with a test case (T1 to T3) for the ratio of pore diameter and grain diameter discriminant method and the Bayesian discrimination method. The three kinds of sand were adopted as the infiltration medium for the verification experiments. Mixed sand (I) was composed by equal amounts of fine sand, medium sand, and coarse sand (II), Mixed sand (II) was composed by a double amount of fine sand, single amounts of medium and coarse sand, and Mixed sand (III) was the raw sand (grain diameter $80 \mu \mathrm{m}$ to $5000 \mu \mathrm{m})$. The grain diameter of suspended solids in recharged water was $0 \mathrm{~mm}$ to $0.1 \mathrm{~mm}$.

\section{Results and Discussion}

\subsection{Suspended Solids Clogging Types}

Based on the experimental results, suspended solids clogging could be divided into three types of surface clogging, inner clogging and mixed clogging.

\subsubsection{Surface Clogging (S)}

Surface clogging indicates that the suspended solids are intercepted by the medium surface when suspended solids grain diameter is larger than pore diameter of infiltration medium (Figure 3a). Characteristics of surface clogging are as follows: (a) the hydraulic conductivity of top layers $(0-3 \mathrm{~cm})$ in column decreases very fast with time, but the hydraulic conductivity of other layers can keep relative stable (Figure 4); (b) TSS of inflow is much greater than outflow because of the filtration effect (Figure 5); and (c) the suspended solids are accumulated only on the surface of sand layer (Figure 6a).

Figure 3. Pictures of different types of suspended solids clogging. (a) Surface clogging (Exp. No.E9); (b) Inner clogging (Exp. No.E2); (c) Mixed clogging (Exp. No.E7).

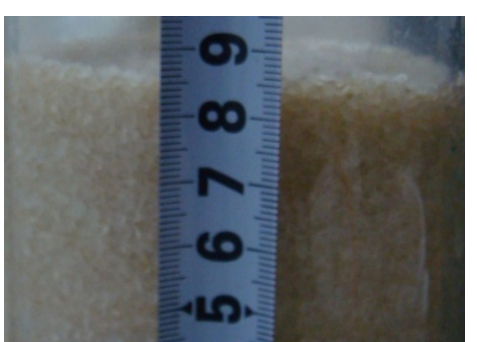

(a)

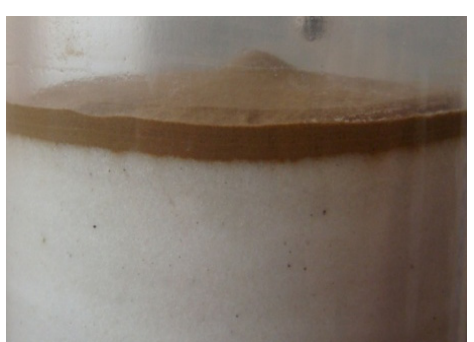

(b)

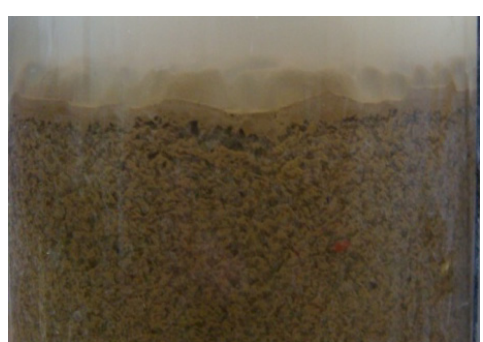

(c) 
Figure 4. K/K0 vs. operation time (Exp. No.E9).

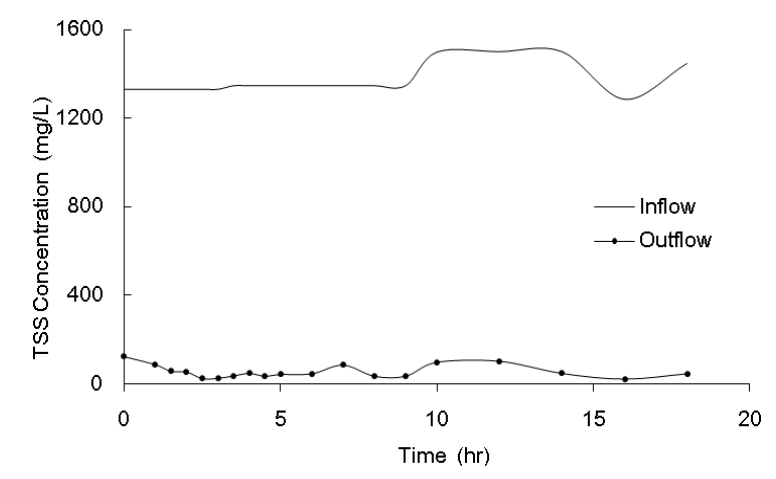

Figure 5. Total suspended solids (TSS) concentration of inflow and outflow.

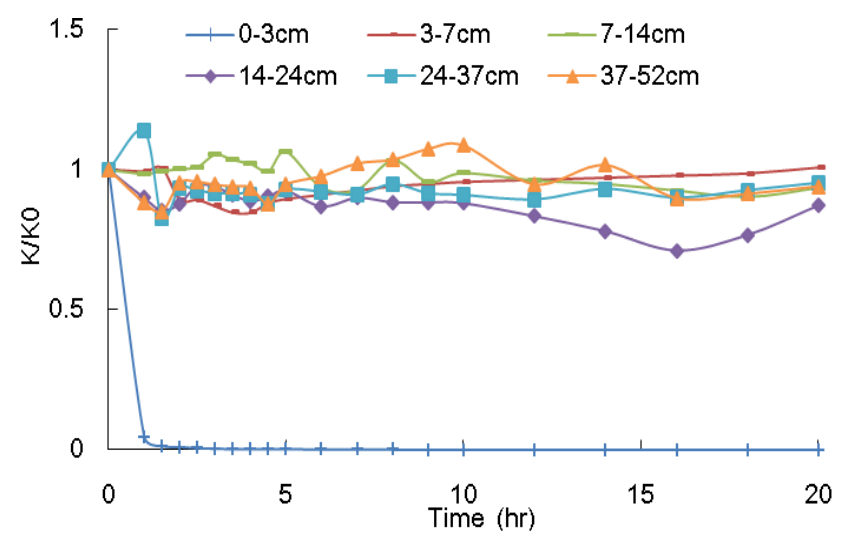

\subsubsection{Inner Clogging (I)}

Inner clogging indicates that the suspended solids particles could transport through the infiltration medium. Only a few suspended solids particles stay in the column, with the majority flowing out with water flow (Figure 3b). The characteristics of inner clogging are as follows: (a) the hydraulic conductivity of all layers in column decreases gradually with time (Figure 7); (b) TSS of inflow is slightly greater than outflow because the filtration effect is not obvious (Figure 8); and (c) the suspended solids are accumulated within the whole column (Figure 6b).

Figure 6. Deposition profile of suspended solids in column. (a) Surface clogging (Exp. No.9);

(b) Inner clogging (Exp.No.2); (c) Mixed clogging (Exp.No.7).

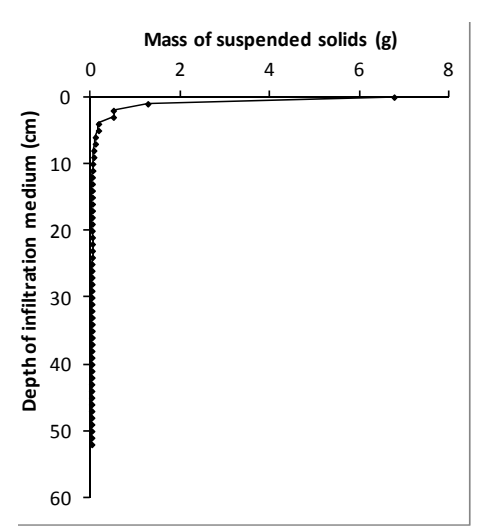

(a)

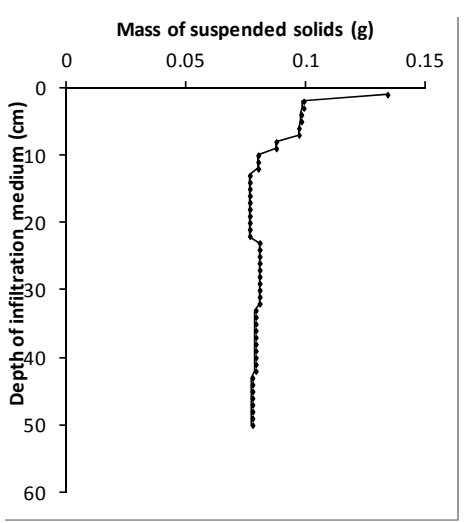

(b)

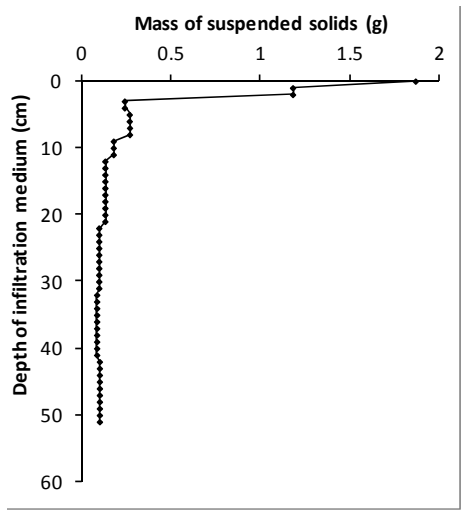

(c) 
Figure 7. $K / \mathrm{K}_{0} v s$. operation time (Exp. No.E2).

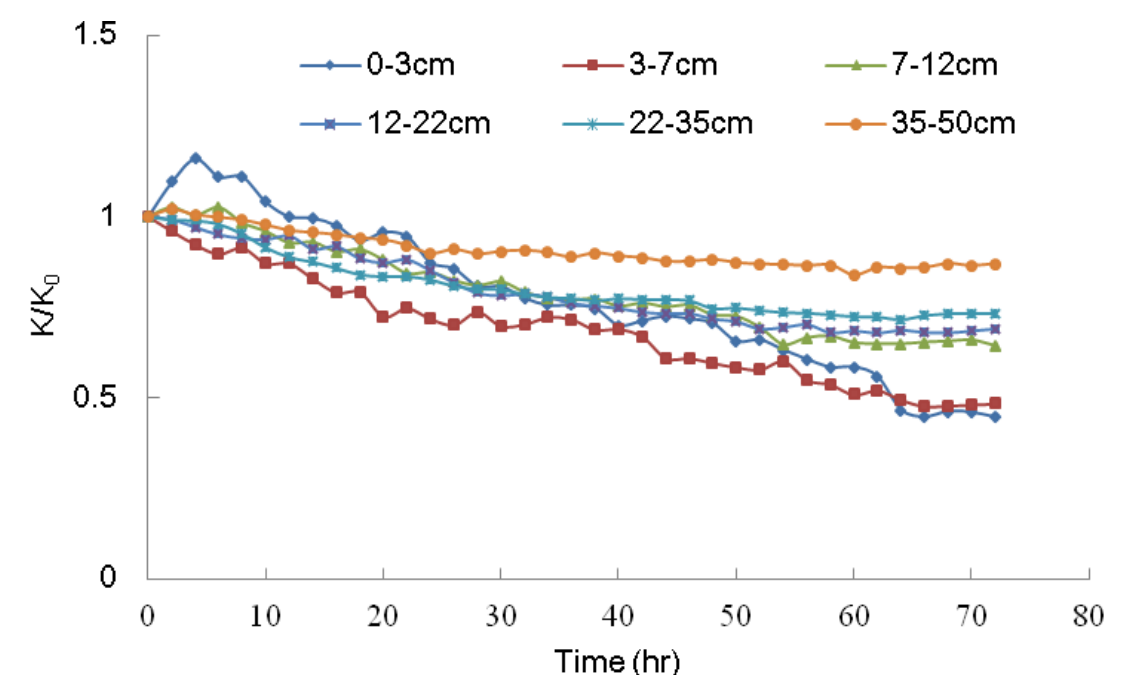

Figure 8. TSS concentration of inflow and outflow (Exp. No.E2).

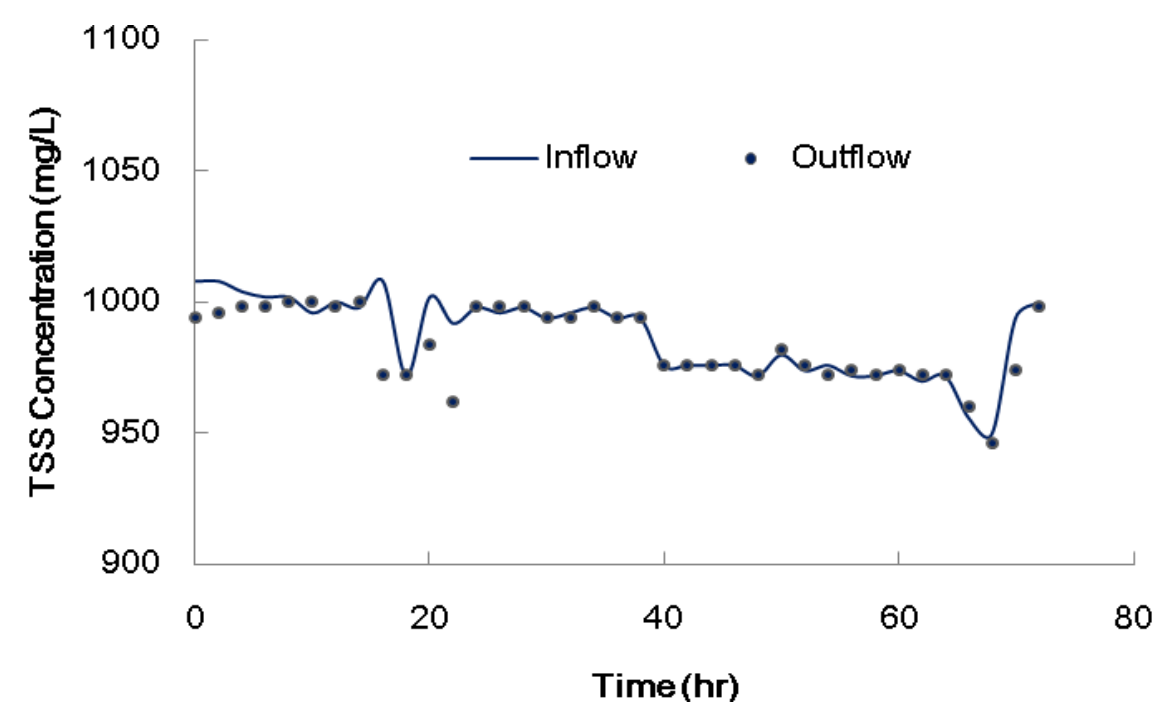

\subsubsection{Mixed Clogging (M)}

Mixed clogging refers to the comprehensive performance of surface clogging and inner clogging. Some small particles can transport for a certain distance through the infiltration medium. As suspended solids continuously accumulate in the flow channel of the medium, the number of suspended solids particles which have the capability to transport through the medium decreases. Suspended solids retention position accumulates upward, ultimately forming a clogging cake on the surface of the infiltration medium [31] (Figure 3c). This clogging mode is a special type of surface clogging that takes longer time to achieve the ultimate clogging state. The characteristics of mixed clogging are as follows: (a) all layer's hydraulic conductivity decreases with time, and the top layer's hydraulic conductivity decreases much faster than other layers (Figure 9); (b) TSS of inflow was greater than outflow, the difference was getting bigger while surface clogging occurred after the time about 30 hours (Figure 10); and (c) the suspended solids were accumulated within the whole sand column, but most of them deposited within depth of $10 \mathrm{~cm}$ (Figure 6c). 
Figure 9. Different depths $K$ vs. operation time (Exp. No.E7).

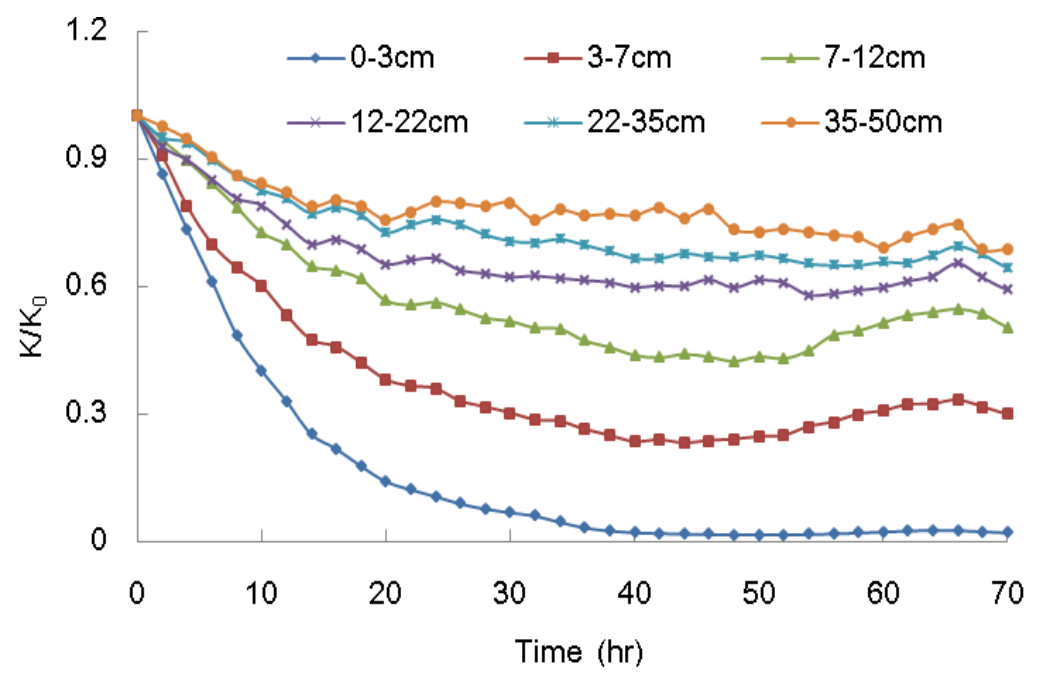

Figure 10. TSS concentration of inflow and outflow (Exp. No.E7).

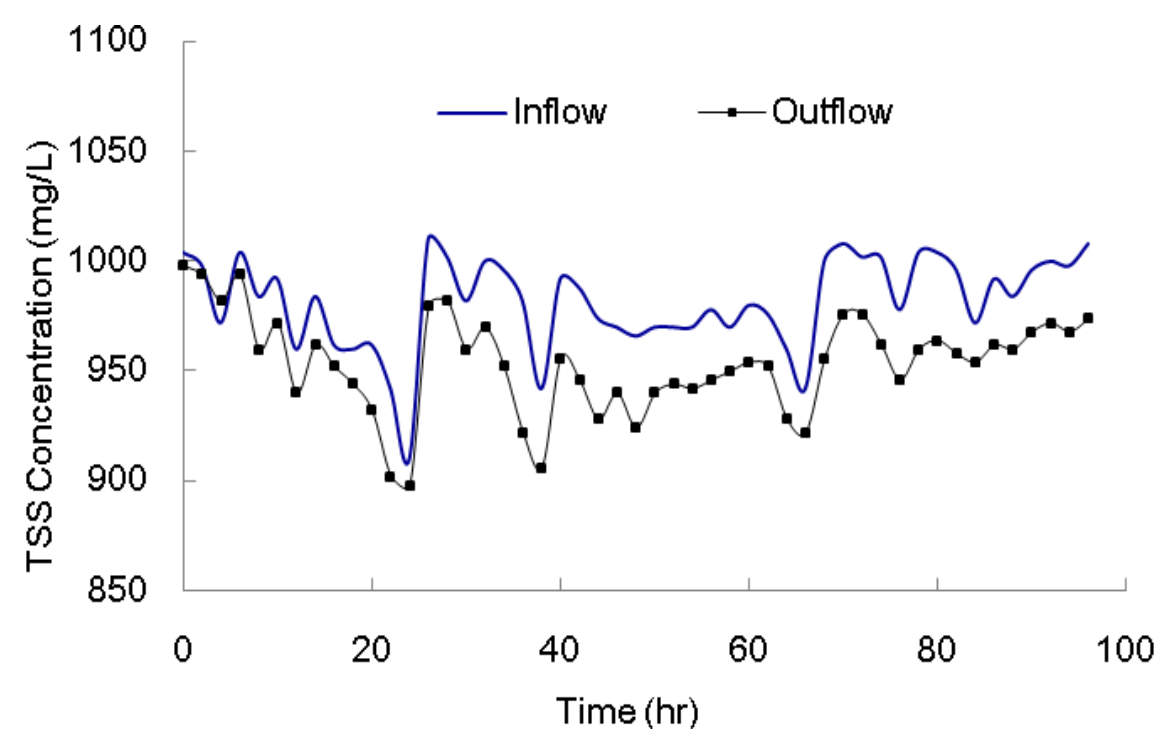

The clogging mechanism, clogging process and the change laws of hydraulic conductivity are differs from different suspended solids clogging types. Thus, the different mathematical models and different prevent and control methods should be varied for each types of suspended solids clogging.

\subsection{Judgment Criteria of Suspended Solids Clogging Types}

Coarse sand (I, II), medium sand, and fine sand in the experiment were basically homogeneous media. Mixed sand is a heterogeneous medium with equal amounts of fine sand, medium sand, and coarse sand (II). Thus, using mean grain diameter, $\mathrm{D}_{50}$, as the effective grain diameter, $\mathrm{D}_{\text {eff, to }}$ calculate effective pore diameter, $\mathrm{D}_{\mathrm{p}}$, is reasonable. The ratio of the infiltration medium of effective pore diameter, $\mathrm{D}_{\mathrm{p}}$, and the grain diameter of all levels of suspended solids, di, was used as the discriminant foundation. Table 2 shows the summary of the calculated $\mathrm{D}_{\mathrm{p}} / \mathrm{d}_{\mathrm{i}}$ using Equations (1) and (2). The classification of suspended solids clogging experiment results could be determined by observing the clogging phenomenon in the experiment, combined with the suspended solids clogging 
characteristics, and then referenced to the result of K-means cluster analysis [32] that uses different groups of $\mathrm{D}_{\mathrm{p}} / \mathrm{d}_{\mathrm{i}}$. Table 3 shows the classification summary.

Table 3. Suspended solids clogging types in laboratory experiments.

\begin{tabular}{cccccc}
\hline Experiment No. & Clogging type & Experiment No. & Clogging type & Experiment No. & Clogging type \\
\hline E2 & I & E10 & S & E17 & M \\
E4 & M & E11 & S & E19 & S \\
E5 & M & E12 & M & E20 & S \\
E6 & M & E14 & S & E21 & M \\
E7 & M & E15 & S & E22 & M \\
E9 & S & E16 & S & & \\
\hline
\end{tabular}

\subsubsection{Ratio of Pore Diameter and Grain Diameter}

Limited by the experimental conditions, the judgment index is $\mathrm{D}_{\mathrm{p}} / \mathrm{d}_{50}$, which represents the ratio of medium pore diameter and median grain size of suspended solids. Theoretically, when $D_{p} / d_{50}$ is less than or equal to a critical value (the theoretical value is 1 ) and the medium pore diameter is less than the suspended solids grain diameter, the suspended solids are intercepted on the surface of medium and form surface clogging. When $\mathrm{D}_{\mathrm{p}} / \mathrm{d}_{50}$ is greater than the critical value, suspended solids are theoretically capable of flowing through the medium freely. However, the judgment criteria based on the experiments are not coincident with the theoretical analysis because of heterogeneity, curve and roughness of pore space. The surface clogging is much easier to occur while $\mathrm{D}_{\mathrm{p}} / \mathrm{d}_{50}<5.5$, the strict inner clogging is hard to happen until $\mathrm{D}_{\mathrm{p}} / \mathrm{d}_{50}>180$, and mixed clogging can be occur while $\mathrm{D}_{\mathrm{p}} / \mathrm{d}_{50}=5.5-180$.

\subsubsection{Bayesian Discrimination Method}

The ratios of medium effective pore diameter $D_{p}$ and levels of suspended solids grain diameter $\mathrm{d}_{10}, \mathrm{~d}_{20}, \ldots, \mathrm{d}_{90}$ are selected as the judgment factors in the Bayesian discriminant analysis model. Using the suspended solids clogging types in the 17 experiments as training samples, Bayesian discriminant analysis can be used to determine the suspended solids clogging type (Equations (9)-(11)).

$$
\begin{gathered}
C_{1}=-1.322-0.585 \mathrm{D}_{\mathrm{p}} / \mathrm{d}_{10}+1.023 \mathrm{D}_{\mathrm{p}} / \mathrm{d}_{30} \\
C_{2}=-3.627-1.789 \mathrm{D}_{\mathrm{p}} / \mathrm{d}_{10}+3.169 \mathrm{D}_{\mathrm{p}} / \mathrm{d}_{30} \\
C_{3}=-155.013-8.913 \mathrm{D}_{\mathrm{p}} / \mathrm{d}_{10}+3.169 \mathrm{D}_{\mathrm{p}} / \mathrm{d}_{30}
\end{gathered}
$$

where $C_{1}, C_{2}$ and $C_{3}$ represent the indicator value of surface clogging, mixed clogging and inner clogging. By substituting the pending samples $D_{p} / d_{10}$ and $D_{p} / d_{30}$ into the model to be calculated, the pending sample category is the group that has the largest $C 1, C 2$, and $C 3$.

\subsection{Case Verification Results}

The discriminant criterion of $\mathrm{D}_{\mathrm{p}} / \mathrm{d}_{50}<$ and Bayesian criteria were also carried out based on the laboratory experiments under the specific infiltration media and suspended solids with nearly uniform particle diameter. The laboratory experiment conditions may not coincide with any real MAR projection. In order to verify the suitability of above criteria, the verification experiments (T1, T2 and T3) 
under more realizable conditions of suspended solids and infiltration media were conducted and analyzed by the methods of $\mathrm{D}_{\mathrm{p}} / \mathrm{d}_{50}$ and Bayesian discrimination (Equations (9)-(11)) (Table 4).

Table 4. Case verification results for different prediction methods.

\begin{tabular}{|c|c|c|c|c|c|c|}
\hline \multirow{2}{*}{ Test No. } & \multirow{2}{*}{$\begin{array}{c}\text { Experimental } \\
\text { observations }\end{array}$} & \multicolumn{4}{|c|}{$\mathbf{D}_{\mathbf{p}} / \mathbf{d}_{\mathbf{5 0}}$} & \multirow{2}{*}{$\begin{array}{l}\text { Bayesian method } \\
\text { predict result }\end{array}$} \\
\hline & & $D_{p}(\mathbf{m m})$ & $\mathrm{d}_{50}(\mathrm{~mm})$ & $\mathbf{D}_{\mathrm{p}} / \mathbf{d}_{\mathbf{5 0}}$ & Predict result & \\
\hline $\mathrm{T} 1$ & $\mathrm{~S}$ & 0.078 & 0.023 & 3.41 & $\mathrm{~S}$ & $\mathrm{~S}$ \\
\hline $\mathrm{T} 2$ & $\mathrm{~S}$ & 0.074 & 0.023 & 3.23 & $\mathrm{~S}$ & $\mathrm{~S}$ \\
\hline T3 & $\mathrm{S}$ & 0.807 & 0.023 & 35.24 & M & $\mathrm{S}$ \\
\hline
\end{tabular}

According to experimental observations, T1, T2, and T3 exhibit surface clogging. Both the prediction results of $\mathrm{D}_{\mathrm{p}} / \mathrm{d}_{50}$ method and Bayesian method are work, and the Bayesian method is more stable and accurate because more factors was considered in the equations.

\section{Conclusions}

Suspended solids clogging in MAR can be classified into three types according to clogging position: surface clogging, inner clogging, and mixed clogging. Surface clogging indicates that the suspended solids are intercepted by the medium surface when suspended solids grain diameter is larger than pore diameter of infiltration medium. The suspended solids are accumulated only on the surface of sand layer and the hydraulic conductivity of top layers decreases very fast with time. Inner clogging indicates that the suspended solids particles could transport through the infiltration medium. The suspended solids are accumulated within the whole column and the hydraulic conductivity of all layers in column decreases gradually with time. Mixed clogging refers to the comprehensive performance of surface clogging and inner clogging. The suspended solids were accumulated within the whole sand column, but most of them deposited within depth of $10 \mathrm{~cm}$. All layer's hydraulic conductivity decreases with time, and the top layer's hydraulic conductivity decreases much faster than other layers.

The prediction of different suspended solids clogging types is very important for design and maintenance of MAR facility. The ratios of medium effective pore diameter, $\mathrm{D}_{\mathrm{p}}$, and levels of suspended solids grain diameter, $\mathrm{d}_{10}, \mathrm{~d}_{20}, \ldots, \mathrm{d}_{90}$ are selected as the judgment index of suspended solids clogging types. $\mathrm{D}_{\mathrm{p}} / \mathrm{d}_{50}$ has a clearer physical meaning in theory and is also easier to apply. Surface clogging occurred while $\mathrm{D}_{\mathrm{p}} / \mathrm{d}_{50}$ was less than 5.5 , inner clogging occurred while $\mathrm{D}_{\mathrm{p}} / \mathrm{d}_{50}$ was greater than 180, and mixed clogging occurred while $\mathrm{D}_{\mathrm{p}} / \mathrm{d}_{50}$ was between 5.5 and 180 . However, the relative ideal conditions of nearly uniform particle diameter of suspended solids, the homogeneous infiltration medium and the limited number of experiments place limitations on the established criterion in practical applications with heterogeneous infiltration medium and non-uniform suspended solids. The scale effect also would play an important role to its application.

The Bayesian discrimination method fully utilizes the ratios of different granularity levels of pore diameter and grain diameter, as well as the statistical relationship based on experimental samples. Under the condition of non-uniform infiltration medium and suspended solids, the misjudgment rate is lower than that of the single pore diameter/grain diameter $\left(D_{p} / d_{50}\right)$ discriminant method, thus exhibiting stronger practicality. With these methods, the potential suspended solids clogging types can be predicted prior to implementation of MAR projection. 
In this study, further development of laboratory experiments on material selection and the number of experiments would further improve the single pore diameter/grain diameter discriminant criterion and Bayesian discriminant model to make these approaches more practical. In addition, further research will involve the testing of other discrimination methods to compare their advantages and disadvantages.

\section{Acknowledgments}

This work was supported by the National Natural Science Foundation of China (No. 40902068, 41002077).

\section{Authors Contributions}

Zijia Wang, Yunqing Fang, Jiawei Hou and Xueyan Ye conducted all the experiments under the guidance of Xinqiang Du. The draft manuscript was finished mainly by Zijia Wang and Yunqing Fang, and the final revision was finished by Xinqiang Du.

\section{Conflicts of Interest}

The authors declare no conflict of interest.

\section{References}

1. Dillon, P.; Pavelic, P.; Toze, S.; Rinck-Pfeiffer, S.; Martin, R.; Knapton, A.; Pidsley, D. Role of aquifer storage in water reuse. Desalination 2006, 188, 123-134.

2. Bouwer, H. Artificial recharge of groundwater: Hydrogeology and Engineering. Hydrogeol. J. 2008, 10, 121-142.

3. Du, X.; Ye, X.; Lu, Y.; Chi, B.; Birk, S.; Yang, Y. Research progress of artificial recharge clogging problem. Adv. Earth Sci. 2009, 24, 973-980.

4. Bekele, E.; Toze, S.; Patterson, B.; Higginson, S. Managed aquifer recharge of treated wastewater: Water quality changes resulting from infiltration through the vadose zone. Water Res. 2011, 45, 5764-5772.

5. Quanrud, D.; Hafer, J.; Karpiscak, M.; Zhang, H.; Lansey, K.; Arnold, R. Fate of organics during soil-aquifer treatment: Sustainability of removals in the field. Water Res. 2003, 37, 3401-3411.

6. Vanderzalm, J.; Page, D.; Barry, K.; Dillon, P. A comparison of the geochemical response to different managed aquifer recharge operations for injection of urban stormwater in a carbonate aquifer. Appl. Geochem. 2010, 25, 1350-1360.

7. Montgomery-Brown, J.; Drewes, J.; Fox, P.; Reinhard, M. Behavior of alkylphenol polyethoxylate metabolites during soil aquifer treatment. Water Res. 2003, 37, 3672-3681.

8. Zhang, J.; Huang, X.; Liu, C.; Shi, H.; Hu, H. Nitrogen removal enhanced by intermittent operation in a subsurface wastewater infiltration system. Ecol. Eng. 2005, 25, 419-428.

9. Schafer, A.; Ustohal, P.; Harms, H.; Stauffer, F.; Dracos, T.; Zehnder, A. Transport of bacteria in unsaturated porous media. J. Contam. Hydrol. 1998, 33, 149-169. 
10. Toze, S.; Bekele, E.; Page, D.; Sidhu, J.; Shackleton, M. Use of static Quantitative Microbial Risk Assessment to determine pathogen risks in an unconfined carbonate aquifer used for Managed Aquifer Recharge. Water Res. 2010, 44, 1038-1049.

11. Anders, R.; Chrysikopoulos, C.V. Virus fate and transport during artificial recharge with recycled water. Water Resour. Res. 2005, 41, doi:10.1029/2004WR003419.

12. Lindsey, G.; Roberts, L.; Page, W. Inspection and maintenance of infiltration Facilities. Soil Water Conserv. 1992, 47, 481-486.

13. Frycklund, C. Artificial Recharge of Groundwater for Public Water Supply. Potential and Limitations in Boreal Conditions. Ph.D. Thesis, Department of Civil Engineering, Royal Institute of Technology (KTH), Stockholm, Sweden, 1998.

14. Chrysikopoulos, C.V.; Masciopinto, C.; La Mantia, R.; Manariotis, I.D. Removal of biocolloids suspended in reclaimed wastewater by injection in a fractured aquifer model. Environ. Sci. Technol. 2010, 44, 971-977.

15. Rinck-Pfeiffer, S.; Ragusa, S.; Sztajnbok, P.; Vandevelde, T. Interrelationships between biological chemical and physical processes as an analog to clogging in aquifer storage and recovery (ASR) wells. Water Res. 2000, 34, 2110-2118.

16. Sniegocki, R.T.; Brown, R.F. Clogging in Recharge Wells, Causes and Cures. In Proceedings of Artificial GRoundwater Recharge Conference, University of Reading, Reading, England, 21-24 September 1970; pp. 337-352.

17. Frycklund, C. Artificial Groundwater Recharge State of the Art; Report 1992-04; Svenska vatten- och avloppsverksföreningen: Stockholm, Sweden, 1998.

18. Custodio, E.; Isamat, J.; Miralles, J. Twenty-five years of groundwater recharge in Barcelona (Spain). Artif. Groundw. Recharg. 1982, 11, 171-192.

19. Iwasaki, T. Some notes on sand filtration. J. Am. Water Works Assoc. 1937, 29, 1591.

20. Phipps, D.; Lyon, S.; Hutchinson, A. Development of a percolation decay model to guide future optimization of surface water recharge basins. In Proceedings of the 6th International Symposium on Managed Aquifer Recharge, ISMAR 6, Phoenix, AZ, USA, 27 October-2 November 2007.

21. McDowell-Boyer, L.M.; Hunt, J.R.; Sitar, N. Particle transport through porous media. Water Resour. Res. 1986, 22, 1901-1921.

22. Pavelic, P.; Dillon, P.J.; Barry, K.E.; Herczeg, A.L.; Rattray, K.J.; Hekmeijer, P.; Gerges, N.Z. Well clogging effects determined from mass balances and hydraulic response at a stormwater ASR site. In Proceedings of the 3rd International Symposium on the Artificial Recharge of Ground Water, Amsterdam, Netherlands, 21-25 September 1998; Peters, J.H., Karsten, H.J., Eds.; Balkema: Amsterdam, the Netherlands; pp. 61-66.

23. Schippers, J.C.; Verdouw, J. The modified fouling index, a method of determining the fouling characteristics of water. Desalination 1980, 32, 137-148.

24. Hauser, V.L.; Lotspeich, F.B. Artificial groundwater recharge through wells. J. Soil Water Conserv. 1967, 22, 11-15.

25. Vecchioli, J. Experimental injection of tertiary treated sewage in a deep well at Bay Park, Long Island, NY. New England. Water Works Assoc. 1972, 86, 87-103.

26. Siriwardene, N.R.; Deletic, A.; Fletcher, T.D. Clogging of stormwater gravel infiltration systems and filters-Insights from a laboratory study. Water Res. 2007, 41, 1433-1440. 
27. Okubo, T.; Matsumoto, J. Biological clogging of sand and changes of organic constituents during artificial recharge. Water Res. 1983, 17, 813-821.

28. Winter, K.J.; Goetz, D. The impact of sewage composition on the soil clogging phenomena of vertical flow constructed wetlands. Water Sci. Technol. 2003, 48, 9-14.

29. Glover, P.W.J.; Walker, E. Grain-size to effective pore-size transformation derived from electrokinetic theory. Geophysics 2009, 74, 17-29.

30. Lachenbruch, P A. Discriminant Analysis; Macmillan Pub Co.: New York, NY, USA, 1975.

31. Wang, Z.; Du, X.; Yang, Y.; Ye, X. Surface clogging process modeling of suspended solids during urban stormwater aquifer recharge. J. Environ. Sci. 2012, 24, 1418-1424.

32. Aldenderfer, M.S.; Blashfield, R.K. Cluster Analysis, 3rd ed.; SAGE Publications Inc.: New York, NY, USA, 1984.

(C) 2014 by the authors; licensee MDPI, Basel, Switzerland. This article is an open access article distributed under the terms and conditions of the Creative Commons Attribution license (http://creativecommons.org/licenses/by/3.0/). 